\title{
Arbuscular Mycorrhizal Fungi (AMF) Induced Defense Factors against the Damping-off Disease Pathogen, Pythium aphanidermatum in Chilli (Capsicum annum)
}

\author{
S. Merina Prem Kumari ${ }^{1 *}$ and N. Srimeena ${ }^{2}$ \\ ${ }^{1}$ Department of Plant Breeding and Genetics, AC\&RI, Killikulam, Tamil Nadu, India \\ ${ }^{2}$ Department of Agricultural Microbiology, AC\&RI, Madurai, Tamil Nadu, India \\ *Corresponding author
}

\begin{tabular}{l} 
K e y w or d s \\
$\begin{array}{l}\text { Arbuscular } \\
\text { mycorrhizal fungi, } \\
\text { Chilli, Leaf and } \\
\text { root, GC-MS } \\
\text { analysis, Defense } \\
\text { factors, Damping- } \\
\text { off pathogen }\end{array}$ \\
Article Info \\
$\begin{array}{l}\text { Accepted: } \\
\text { 17 May } 2019 \\
\text { Available Online: } \\
\text { 10 June } 2019\end{array}$ \\
\hline
\end{tabular}

\author{
A B S T R A C T
}

\section{Introduction}

Arbuscular Mycorrhizal Fungi in symbiotic association with crop plants, improve not only the phosphorus nutrition of the host plant but also its growth and increases resistance to drought and diseases. AMF in its association with crop plants, receive greater attention for
Arbuscular Mycorrhizal Fungi (AMF) from the small phylum Glomeromycota forms symbiotic association with the roots of higher plants. The AMF appears to benefit by improving the uptake of phosphate and other nutrients from soil and also increases the disease tolerance to the host plant. Mycorrhizal plants produce certain substances that have been indicated as copartners in resistance to the attack of root pathogens. The GC-MS analysis of root and leaf samples of AMF inoculated plants of chilli infected with the damping off disease pathogen, Pythium aphanidermatum, a tripartite interaction (chilliAMF-pathogen) indicated the presence of compounds such as carboxy-1-methyl-2azetidione, 1,2-cyclobutanedicarboxylic acid, tetra hydrogeranyl-2-methyl butyrate, 1, 2benzenedicarboxylic acid and benzaldehyde that are reported as potential defense factors by various authors. Fatty acids with antimicrobial properties are also detected in both leaf and root samples of AMF inoculated chilli plants infected by damping-off pathogen. Dibutyl phthalate is a bioactive compound that was present at high level in leaf samples of AMF treated plants. Shahamin-B, a diterpenoid with anti-feedant properties was detected in chilli leaves due to AMF treatment. The results clearly reveal that the defense factors were induced by the mycorrhizal plants at higher level compared to non-mycorrhizal plants that in turn hinder the establishment of the pathogen. This strategy occurring in crop plants due to AMF colonization in roots is documented to prevent the incidence of pathogen attack, thereby enhancing the growth and yield of crop plants. 
used in the biological control of plant diseases, considering that they are widely distributed and establish long time relationships with the roots of most plant species. In several cases direct biocontrol potential has been demonstrated, especially for plant diseases caused by Phytophtora, Rhizoctonia, and Fusarium pathogens (Azcon and Barea, 1997). The colonization of common bean plants with AMF reduced the Rhizoctonia root rot disease incidence and severity due to accumulation of phenolic compounds and defense related enzymes (Abdel-Fattah et al., 2011). The mycorrhizal fungi are capable of producing morphological and physiological modifications in the root cells that increase plant's tolerance to root diseases.

Mycorrhizal plants produce certain substances that have been indicated as copartners in resistance to the attack of root pathogens. Phenols, particularly flavonoids and isoflavonoids, are secondary metabolites involved in plant-microorganism interactions. The phytoalexins show defense role, which are important in plant protection mechanisms. Phormononetina and biocanina- $A$ are the phenolic compounds with defense properties found in the roots of mycorrhizal plants (Lambais, 1996; Santos et al., 2017). Because of the defense mechanism by AMF in crop plants, this study is conducted to demonstrate the induction of defense factors in chilli plants due to the colonization of AMF in its rhizosphere.

\section{Materials and Methods}

Analysis of defense factors by gas chromatography-mass spectrometry

The analysis of the defense factors in the roots and leaves of AMF colonized chilli plants infected by damping-off pathogen was done by GC-MS (Seher et al., 2006).

\section{Preparation of plant extracts}

The root and leaf samples of Pythium aphanidermatum inoculated chilli plants that were both colonized and uncolonized by AMF were taken at the time of flowering for GCMS analysis. The leaves and roots were dried at $30^{\circ} \mathrm{C}$. The dried leaves and roots were crushed into fine particles and $10 \mathrm{~g}$ of the powdered samples were soaked in $100 \mathrm{ml}$ of $100 \%$ methanol for 72 hours at room temperature with occasional mixing. The extract was then filtered using Whatman no.1 filter paper. The filtrates were concentrated in rotary vacuum evaporator and then the samples were filtered through membrane filter.

\section{GC-MS analysis}

The samples were analyzed using Clarus500 MS equipment. The column thickness of $30 \mathrm{~m}$ $\mathrm{x} 0.25$ micron was used. Helium was used as the carrier gas. Temperature program: 80$240^{\circ} \mathrm{C}$ at $8^{\circ} \mathrm{C} \cdot \mathrm{min}^{-1}, 240-300^{\circ} \mathrm{C}$ at $12^{\circ} \mathrm{C} \cdot \mathrm{min}^{-1}$ and a $5 \mathrm{~min}$ hold at $300^{\circ} \mathrm{C}$. The identification of components was accomplished using computer searches in commercial libraries..

\section{Results and Discussion}

The presence of defense factors in leaf and root samples of damping-off pathogen infected chilli plants that were AMF colonized and uncolonized was done by GCMS and the compounds were identified as fatty acids and terpenoids.

\section{GC-MS pattern of chilli leaf analytes}

The leaf samples collected from AMF colonized and uncolonized chilli plants inoculated with Pythium aphanidermatum were used to identify the defense factors. The AMF treated and untreated chilli plant leaf samples showed the presence of various 
compounds. AMF untreated chilli leaves revealed various biomolecules viz., pentanoic acid, 2- butyl ester, 1-2-bromododecanoic acid, 2-butene-1,4-diamine, 3-ethyl pentane, dibutyl phthalate, methyl palmitate, 1,2propanedione, dodecane, 1-fluuorodecyclic acid and ethyl-o-nitrobenzylidenentranilate. The AMF treated chilli plant leaf samples contained the defense factors viz., butanoic acid, tetra hydrogeranyl-2-methyl butyrate, propanoic acid, 1,2- benzenedicarboxylic acid, dibutyl phthalate and palmitic acid and these compounds were not found in AMF untreated chilli plants. Among the defense factors, the dibutyl phthalate, a diester of phthalic acid, is a bioactive defense factor that showed major peak in AMF treated plants, but the same compound was found in low level in AMF untreated plants. Shahamin-B, a diterpenoid with antifeedant properties is present only in the AMF treated leaves (Table $1)$.

\section{GC-MS pattern of chilli root analytes}

The defense factors present in root samples of AMF colonized chilli plants inoculated with Pythium aphanidermatum are carboxy-1methyl-2-azetidinone, 1,2-cyclobutane dicarboxylic acid, benzaldehyde, didodecyl phthalate, butanoic acid and oleic acid. The carboxy-1-methyl-2-azetidione is the compound present only in AMF treated root sample and in this compound the azetidinone is highly antimicrobial. 1, 2cyclobutanedicarboxylic acid is a diester compound that exhibits defense role. Two fatty acids viz., butanoic acid and oleic acid with defense activity are present in the AMF colonized roots. Benzaldehyde is an aldehyde compound, which has antifungal and nematicidal activities. The didodecyl phthalate is a diester of phthalic acid, and it is a bioactive compound. Capric acid, a defense factor is also present in AMF colonized chilli plants.

Table.1 The defense factors detected by GC-MS in the leaves and roots of damping-off pathogen infected chilli plants colonized with AMF

\begin{tabular}{|c|l|l|}
\hline S.No & \multicolumn{1}{|c|}{ Defense factors in chilli leaves } & \multicolumn{1}{|c|}{ Reference in which cited earlier. } \\
\hline 1. & Butanoic acid & Browing et al., 2005 \\
\hline 2. & Propanoic acid & Kitahara et al., 2004 \\
\hline 3. & 1,2-benzenedicarboxylic acid & Sayed et al., 2008 \\
\hline 4. & Dibutyl phthalate & Weiwei et al., 2008 \\
\hline 5. & Palmitic acid & Mishra and Sree, 2007 \\
\hline 6. & Tetra hydrogeranyl 2 methyl butyrate & Gokalp et al., 2003 \\
\hline & Defense factors in chilli roots & \\
\hline 1. & Carboxy-1-methyl-2-azetidinone & Chavan and Nandini, 2007. \\
\hline 2. & 1,2-cyclobutanedicarboxylic acid & Sayed et al., 2008 \\
\hline 3. & Benzaldehyde & Shaukat et al., 2005 \\
\hline 4. & Didodecyl phthalate & Gokalp et al., 2003 \\
\hline 5. & Butanoic acid & Browing et al., 2005 \\
\hline 6. & Oleic acid & Kitahara et al., 2004 \\
\hline
\end{tabular}

The biomolecules present in AMF uncolonized roots were 5-hydroxy methyl-2furanone, 1-methyl-2ethyl-pyazolium bromide, 3-methyl-2-furan, 3- diazoundecan2-one, decanoic acid, 2,5,6-trimethyl-4-ethyl pyrimidine, hexadecanoic acid, ethyl 5,5- 
dimethyl cyclohex-2-en-1-one, 2,4hexadienyl alpha-diazoacetate, capric acid, docosanedioic acid and ethyl phosphonic acid. But these compounds are absent in AMF colonized roots (Table 1). The results revealed comparatively more number and quantity of defense factors in the roots of AMF colonized chilli than the AMF uncolonized chilli plants.

\section{Defense factors in the leaves}

The GC-MS analysis of the AMF treated and untreated leaf samples of chilli plants inoculated with Pythium aphanidermatum showed the differences in the presence of various compounds. The AMF colonized chilli leaf samples contained compounds viz., butanoic acid, tetrahydrogeranyl-2-methyl butyrate, propanoic acid, shahamin B, 1,2benzenedicarboxylic acid, dibutyl phthalate and palmitic acid, whereas these compounds were not present in AMF uncolonized chilli. And these compounds are reported as potential defense factors by Kitahara et al. (2004) who studied the defense role of some fatty acids viz., octanoic acid, decanoic acid, lauric acid, myristic acid, palmitic acid and stearic acid. Gonzalez (2007) studied the biological activities of diterpenoids and observed that shahamin-C is an antifeedant compound. Gokalp et al. (2003) studied the biological activity of some of the compounds viz., 3-methyl-2-buten-1-ol, butyl-2- methyl butyrate, octyl acetate, decanol etc. Weiwei et al. (2008) identified that some of the volatile organic compounds viz., dibutyl phthalate, acetic acid, o-xylene, 3-octanone, 2-decanne act as defense factors against fungi. Mishra and Sree (2007) identified the defense factor, palmitic acid in the leaves of mangrove plant by GC-MS analysis. Browing et al. (2006) found that butyric acid acts against soil borne fungal pathogen and nematode in strawberry. Shahamin-B is a diterpenoid that was present in the leaves of AMF colonized chilli and this compound possesses antifeedant properties. The presence of defense factors in AMF treated chilli leaves show the tolerance of the crops to disease causing pathogens.

\section{Defense factors in the roots}

The compounds present in AMF colonized chilli root samples are carboxy-1-methyl-2azetidinone, 1,2-cyclobutanedicarboxylic acid, benzaldehyde, didodecyl phthalate, butanoic acid and oleic acid and these compounds also possess the defense role. Sayed et al. (2008) found that Phenazine-1carboxylic acid acts against Alternaria solani. Benzaldehyde is found to be potential compound for the control of both fungal pathogens and phytoparasitic nematodes (Shaukat et al., 2005). Walker et al. (2003) observed the defense factors viz., butanoic acid, trans-cinnamic acid, O-coumaric acid, ferulic acid and vannilic acid in Arabidopsis thaliana by HPLC. Azetidinones are known to exhibit interesting biological activities (Chavan and Nandini, 2007). Capric acid is a fatty acid compound found in AMF colonized chilli plants. But the level of the capric or decanoic acid is less because the AMF colonized plants are induced to increase the synthesis of other defense factors.

Arbuscular mycorrhizal fungi are responsible for the alteration of genetic expression, mitochondrial and plastid proliferation of the host plants and increased production of terpenoids and jasmonic acid for defense against the pathogen (French, 2017). AMF have been used in the biological control of plant diseases, considering that they are widely distributed and establish long time relationships with the roots of most plant species. Mycorrhizal plants produce certain biomolecules that have been responsible for resistance to the attack of root pathogens. The presence of these defense factors in the leaf and root extracts of AMF colonized chilli 
inoculated with Pythium aphanidermatum indicate that these compounds play a major role in the control of root pathogens. This implies that the host plants undergo certain important changes in the plant's primary and secondary metabolism and regulation of the plant defense mechanisms (Fester and Hause, 2005; Sabin et al., 2012) altering the ability of the crops to sustain stresses. The transcriptomic and proteomic profiling of roots and leaves of wheat in symbiosis with AMF and infected with Xanthomonas translucens confer stronger productivity and enhanced resistance to $X$. translucens (Fiorilli et al., 2018). During mycorrhiza establishment, induction of plant defense responses occurs, thus achieving an efficient activation of the plant immune responses leading to defense mechanisms to attack the pathogens (Jung et al., 2012). The protective effect of the plant - mycorrhizal symbiosis against pathogens leading to the crop protection is proved to be an altered metabolism of plants to overcome the stress caused by the disease causing pathogens.

\section{References}

Abdel-Fattah.G.M, S.A.El-Haddad and E.E. Hafez. 2011. Induction of defense responses in common bean plants by arbuscular mycorrhizal fungi. Microbiological Research. 166(4): 268-281.

Azcon, A.C. and Barea, J. M. 1997. Arbuscular mycorrhizas and biological control of soil borne plant pathogens: an overview of the mechanisms involved. Mycorrhiza. 6: 457-464.

Browing, M., D.B. Wallace, C. Dawson, S.R. Alm and Amador, J.A. 2006. Potential of butyric acid for control of soil borne fungal pathogens and nematodes affecting strawberries. Soil Biology and Biochemistry. 38: 401404.
Chavan, A.A. and Nandini, R.P. 2007. Synthesis and Biological activity of Nsubstituted-3- chloro-2-azetidinones. Molecules. 12: 2467-2477.

Chen, M, M. Arato, L. Borghi, E.Nouri, and Reinhardt, D. 2018. Beneficial Services of Arbuscular Mycorrhizal Fungi - From Ecology to Application. Front Plant Sci., .9: 1270.

Fester, T. and Hause, G. 2005. Accumulation of reactive oxygen species in arbuscular mycorrhizal roots. Mycorrhiza. 15:373-379.

Fiorilli. V, C. Vannini, F. Ortolani, D.GarciaSeco, M. Chiapello, M. Novero, G. Domingo, V. Terzi, C. Morcia, P. Bagnaresi, L. Moulin, M. Bracale and Bonfante, P. 2018. Omics approaches revealed how arbuscular mycorrhizal symbiosis enhances yield and resistance to leaf pathogen in wheat. Scientific Reports. 8: 9625.

French, K.E.2017. Engineering Mycorrhizal Symbioses to Alter Plant Metabolism and Improve Crop Health. Front.Microbiol. 8:1403.

Gokalp, I, D. Fatih, K.Mine, K.Merih and Husnii, K.C.B. 2003. The bioactive essential oil of Herardeum spondylium L.sub sp. ternatum (velen.) Brummitt. $33^{\text {rd }}$ symposium on essential oils $\left(33^{\text {rd }}\right.$ ISEO). pp. 195-200.

Gonzalez, M.A. 2007. Spongiane diterpenoids. Current bioactive compounds.3: 1-36.

Jung, S.C, A.M. Medina, J.A.L. Raez, and Pozo, M.J. 2012. Mycorrhiza-induced resistance and priming of plant defenses J. Chem. Ecol. 38: 651- 664.

Kitahara, T, K. Nao, J. Matsuda, Y. Aoyana, Y. Hirakata, S. Kamihira, S.Kohno, M. Nakashima and Sasaki, H. 2004. Antimicrobial activity of saturated fatty acids and fatty amines against methicillin-resistant staphyloccus aureus. Bio. Pharm. Bull. 27(9): 1321- 
1326.

Lambais, M.R. 1996. Aspectos bioquimicos e moleculares da relacao fungoplantaem microrrhizas arbusculares. In: Avancos em Fundamentos e Aplicacao de Micorrhizas Lavras, Brazil: Universidade Federal de Lavras. (eds., J.O. Siqueira ). pp.5-38.

Mishra, P.M. and Sree, A. 2007. Antibacterial activity and GC-MS analysis of the extract of leaves of Finlaysonia obovata. Asian Journal of Plant Sciences. 6(1):168-172.

Orlando, A.Q. 2003. The vesicular arbuscular mycorrhizal symbiosis - A review. Afr. J.Biotechnol. 2: 539-546.

Sabine.C.J, A.M.Medina, J.A.L.Raez and Pozo,M.J.2012.Mycorrhiza-Induced Resistance and Priming of Plant Defenses. J Chem Ecol. 38:651-664.

Santos,E.L, F.A.Silva and Silva, F.S.B. 2017. Arbuscular Mycorrhizal Fungi increase the phenolic compounds concentration in the bark of the stem of Libidibia ferrea in field conditions. The Open Microbiology Journal. 11:283-291.

Sayed, W.E., M.A.E. Megeed, A.B. Abd ElRazik, K.H. Soliman and Ibrahim,
S.A. 2008. Isolation and identification of phenazine-1- carboxylic acid from different Pseudomonas isolates and its biological activity against Alternaria solani. Research Journal of Agriculture and Biological Science. 4(6): 892-901.

Seher, G, D.T. Balik and Nazmi, G. 2006. Antimicrobial activities and some fatty acids of turmeric, ginger root and linseed used in the treatment of infectious diseases. World J. of Agrl. Sci. 2(4): 439-442.

Shaukat, S.S, J.A.Siddqui and Munir, N. 2005. Nematicidal, antifungal and phytotoxic responses of Coryza Canadensis. Plant Pathology Journal. 4: 61-68.

Walker, T.S., P.B. Harish, M.H. Kathleen, F.S. Frank and Jorge, M.V. 2003. Metabolic profiling of root exudates of Arabidopsis thaliana. J. Agri. Food. Chem. 51: 2548-2554.

Weiwei, L, M. Wei, Z. Bingyu and Feng, L. 2008. Antifungal activities and components of VOCS produced by Bacillus subtilis $\mathrm{G}_{8}$. Current Research in Bacteriology. 1: 28-34.

\section{How to cite this article:}

Merina Prem Kumari, S. and Srimeena, N. 2019. Arbuscular Mycorrhizal Fungi (AMF) Induced Defense Factors against the Damping-off Disease Pathogen, Pythium aphanidermatum in Chilli (Capsicum annum). Int.J.Curr.Microbiol.App.Sci. 8(06): 2243-2248.

doi: https://doi.org/10.20546/ijcmas.2019.806.267 